\title{
Risk of Leukaemia in Czech Uranium Miners
}

\author{
Ladislav Tomasek ${ }^{1 *}$, Robert Reřicha $^{2}$ \\ ${ }^{1}$ National Radiation Protection Institute, Prague, Czech Republic \\ ${ }^{2}$ Center of Epidemiological Studies, Př́ibram, Czech Republic
}

Introduction: Epidemiological studies among uranium miners have evidenced lung cancer risk in relation to radon exposure. Although leukemia is especially sensitive to induction by radiation, the assessment of leukemia risk in uranium miners is more complex as its incidence is substantially lower than that of lung cancer. One of first results of leukaemia risk was reported by Rerricha in 2006 and was based on case cohort approach with 84 leukaemia cases analysed in relation to cumulated exposure of radon decay product. However, the assessment of the risk is more complex because the radiation risks in mines involve exposure to radon, external gamma radiation, and exposure to airborne long lived radionuclides arising from uranium ore dust.

Results: Recent follow-up of a Czech study of 10000 uranium miners have resulted in 54 leukaemias. The risk is evaluated in relation to cumulated equivalent doses from radon, long lived radionuclides (LLR), and external gamma. The mean equivalent doses to the red bone marrow in the entire study are $33 \mathrm{mSv}$ from radon, $46 \mathrm{mSv}$ from external gamma radiation, and $106 \mathrm{mSv}$ from long lived radionuclides. Mean doses among leukaemia cases are nearly twice. The excess relative risk per $\mathrm{Sv}(\mathrm{ERR} / \mathrm{Sv})$ in this study is $3.8(90 \%$ confidence interval $1.0-10.5)$ is statistically significant $(\mathrm{p}=0.008)$. This value is consistent with the leukaemia risk observed in the Life Span Study among Japanese survivors of A bombing $(\mathrm{ERR} / \mathrm{Sv}=4)$. These results will be compared to earlier results by Rerricha using the same approach in relation to exposure to radon, external gamma radiation, and exposure to long lived radionuclides.

The study was supported by the Ministry of the Interior of the Czech Republic, project No. MV-25972-2/OBV-2012-2017.

* Corresponding author: ladislav.tomasek@suro.cz 